Article

\title{
Characterization of the Anti-Graffiti Properties of Powder Organic Coatings Applied in Train Field
}

\author{
Stefano Rossi ${ }^{*}{ }^{\dagger}$, Michele Fedel $^{\dagger}{ }^{\dagger}$, Simone Petrolli ${ }^{\dagger}$ and Flavio Deflorian ${ }^{\dagger}$ \\ Department of Industrial Engineering, University of Trento, Via Sommarive, 9, 38123 Trento, Italy; \\ michele.fedel@unitn.it (M.F.); petrolli.simone@gmail.com (S.P.); flavio.deflorian@unitn.it (F.D.) \\ * Correspondence: Stefano.rossi@unitn.it; Tel.: +39-0461-924069 \\ + These authors contributed equally to this work.
}

Academic Editor: Mariateresa Lettieri

Received: 18 March 2017; Accepted: 28 April 2017; Published: 6 May 2017

\begin{abstract}
The widespread prevalence of the phenomenon of graffiti and the growth of the removal cost—in particular in public transport systems-has pushed the research for technical solutions to this problem. Suitable solutions to address graffiti-related concerns are needed in order to reduce the cleaning costs as well as the downtime of trains. Graffiti are a big problem for painted metal, because the protective coatings and graffiti have the same chemical nature (polymeric matter). A permanent coating is expected to be able to resist the highest possible number of cleanings of the graffiti without modifying its aesthetic and corrosion protection properties. The purpose of this study is to develop a methodological approach for the characterization of graffiti-resistant organic coatings. For this purpose, a critical review of the existing standards is carried out. The anti-graffiti properties of a polyurethane organic coating were investigated before and after accelerated weathering. In order to understand the behavior of the coatings during cleaning, the aging of the coating in contact with the remover was carried out. The effect on the corrosion protection properties was assessed during the accelerated aging. The resistance of the coating was proved to be strongly affected by the surface finishing. UV exposure modified surface properties and graffiti removal efficiency.
\end{abstract}

Keywords: organic coating; painted metal; graffiti; graffiti cleaning agents

\section{Introduction}

The problem of graffiti originated in the second half of the last century, causing a lot of damages to transport vehicle bodyworks as well as to buildings and public areas [1-3]. The cost of graffiti removal is very high. Therefore, the coating industry has developed permanent solutions for minimizing the cleaning costs. For the urban administration and transportation companies, the damage caused by graffiti presents considerable costs. In 2007, in Australia, the rolling stock graffiti removal cost was $\$ 12$ million and $\$ 8$ million for railway infrastructure [4]. In 2014, a study reported that the cost of cleaning Milano (Italy) of graffiti would have been 100 million euros [5]. Trenord (the railroad agency of the Lombardia region, Italy) evaluated the cost of vandalism including the graffiti removal to be approximately 8 million euros [6]. From a technological point of view, there are two kinds of anti-graffiti products [7]. The first one consists of a "sacrificial" layer (commonly wax-based coatings) which is removed during the cleaning. The removal is carried out using hot water jet $[8,9]$. The second technological solution is a permanent layer which is not solubilized during graffiti removal. This solution is also well considered, not only on metallic substrates, but also on stone and concreate $[10,11]$. The permanent coatings are designed to withstand frequent and repeated cleaning cycles [12-14]. The choice of a permanent coating involves a larger initial cost, repaid in the following years thanks to a faster and more effective cleaning. The selection between the first and the second solution is influenced by some aspects. One of the most important is the cost of the coating and the revamping of 
the anti-graffiti system. In the train field, the actual trend is to move to the application of a permanent layer due to the reduction of graffiti removal time, thus avoiding long standstill of the rolling stock.

Polyurethane resins show good mechanical properties and high chemical resistance. The latter is needed to guarantee a sufficient solvent resistance, and therefore, corrosion resistance $[15,16]$. As far as polyurethane-based formulations are concerned, UV radiation resistance is critical. Ultra-violet radiation is recognized to affect the molecular bonds of the polymeric matrix and additives, thus leading to modifications of properties of the coating [17]. In the last years, a lot of solutions were investigated adding some additives (e.g., UV-absorbers) to the blend. Widely-accepted procedures to evaluate the properties of anti-graffiti coatings have been developed and are described in ASTM as well as in UNI standards. These standards referring to anti-graffiti evaluation present different critical points. In particular, in ASTM D6578 [18], several graffiti marking materials and removal agents are indicated. Thus, the testing of all the possible combinations of marking materials and removers is possible after considerable time and effort. Moreover, no limit to the re-cleanability procedure is indicated. This aspect is believed to be very important due to the frequency of graffiti damage-particularly on railroad components and materials. Considering this aspect, the UNI 11246 [19] standard seems more useful, as it indicates in ten, the maximum number of graffiti production and removal. However, this standard is believed to provide a relatively restricted threshold to consider a graffiti-resistant coating as acceptable. Starting from the approach recommended in the cited standards, the aim of this paper is to individuate a suitable method to characterize the anti-graffiti properties of organic coatings. The idea is to overcome the limits of the current ASTM and UNI standards, suggesting a different testing approach in order to fully understand the effect of the cleaning mechanism. A review of the existing standard would help to get some insight into the anti-graffiti coating durability, thus leading to a better improvement of both coating and remover formulation. For this aim, a polyurethane powder coating which is widely used on transport and infrastructure as a protection system [15,20-22] is considered. This application method is used in industrial plants to cover unpainted metallic substrates. In the case of degraded painted surfaces, to guarantee a good adhesion between paint and substrate, it is necessary to remove the old organic coating before application. The polymeric matrix was modified, changing the additives to reach two different surface finishes. Considering the importance of the damage produced by UV exposure and chemical solvent contact, these aspects are the object of another paper [17].

\section{Materials and Methods}

A polyurethane powder coating was deposited on Aluminum alloy 1050 ( $\min 99.50 \% \mathrm{Al}$ ) panels. Two different coating finishes-obtained by modifying the additives in the paint-were investigated: smooth ( $S$, roughness $R_{\mathrm{a}}$ in the range of $1 \mu \mathrm{m}$ ) and wrinkled ( $W$, roughness $R_{\mathrm{a}}$ in the range of $25 \mu \mathrm{m})$. The surface roughness was measured by profilometer Mahr mod. MarSurf PS1 on a stretch of length $5.6 \mathrm{~mm}$. Aluminum was selected as substrate considering the growing interest for lightweight materials both in the transport of both constructions. The polymeric blend consisted of a hydroxylated polyester resin based on terephthalic acid and neopentylglycol. The hardener agent was a polyisocyanate adduct blocked with caprolactam and uretidione. The coating layer was applied by a powder deposition method. Before deposition, the raw aluminum surface was degreased with acetone for $10 \mathrm{~min}$. The powder consisted of a pre-blended mixture of resins, hardener, pigments, and additives. The powder was electrostatically applied on the substrate prior to a thermal treatment, which promoted melting and curing $[21,23,24]$. In our case, the curing process was performed at $190{ }^{\circ} \mathrm{C}$ for $20 \mathrm{~min}$. The color of this permanent paint was grey (RAL 7035). The paint was opaque and completely covered the metallic aspect of the aluminum surface.

First, the coating was characterized with an optical microscope to verify the presence of macro and micro defects. Figure 1 shows the surface of both samples: observe the different surface roughness. 


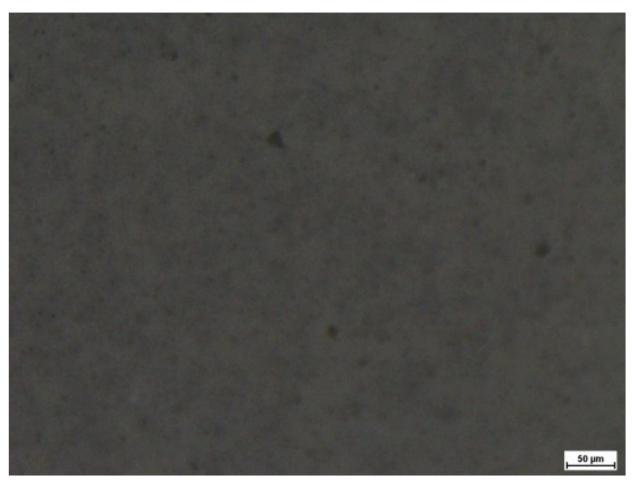

(a)

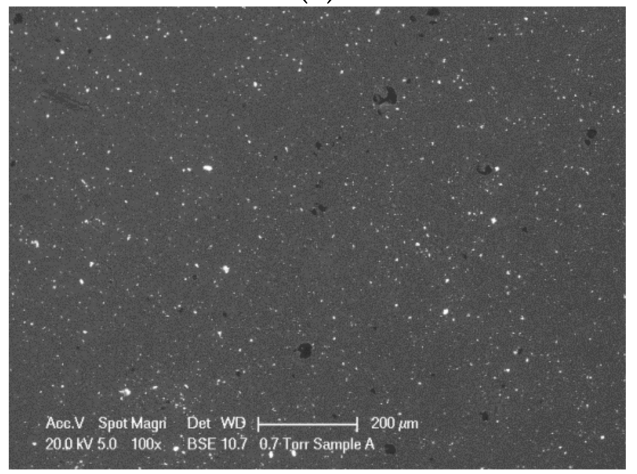

(c)

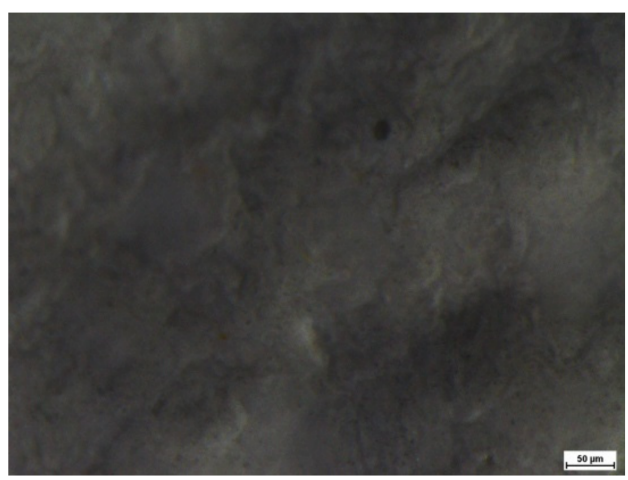

(b)

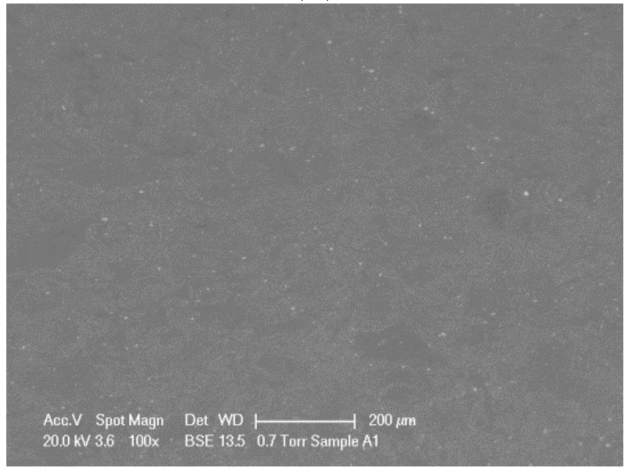

(d)

Figure 1. Optical and electronic pictures of surface of smooth sample $(\mathbf{a}, \mathbf{c})$ and wrinkled one $(\mathbf{b}, \mathbf{d})$.

The anti-graffiti behavior was evaluated considering some prescriptions of ASTM D6578 standard [18]. This standard indicates the application of different materials typically used as graffiti markings. The anti-graffiti behavior is evaluated considering the complete removal of graffiti by the mechanical action of a cotton cloth embedded with different cleaning agents (without producing any damage on the coating). To evaluate the clearness, visual observation or gloss and color change measurements are considered.

Considering the graffiti marking materials indicated in the standard, the graffiti were simulated using a red acrylic spray paint (AREXONS Acril color [25]), because sprayed coatings represent the most used damage methods in an urban environment. A $2.5 \mathrm{~cm} \times 2.5 \mathrm{~cm}$ mask was employed in order to limit the graffiti areas. The surface was colored maintaining a $30 \mathrm{~cm}$ spraying distance in order to obtain a homogeneous layer of acrylic paint. According to the standard and the acrylic paint supplier recommendation, the samples were cured at room temperature. The graffiti removal was done using a white cotton cloth soaked in the remover at room temperature without water addiction. Several standard cleaning agents are indicated in the ASTM D6578 [18]. Nevertheless, some of them are too soft (for example, lint-free cotton cloth, mild detergent-based on sodium phosphate). The choice of removers to understand the cleaning mechanism was made considering chemical species such as MEK (methyl ethyl ketone, a polar aliphatic organic solvent), and xylene, an apolar aromatic solvent. The selection of this remover was made considering possible chemical interaction with the organic coating. The ideal solvent should remove the graffiti paint while only slightly affecting the properties of the underlying coating.

The cleaning was done as long as the surface would have been completely cleaned or a further cleaning action would have resulted ineffective. Following the guidelines of the cited standards, a visual evaluation of the completely cleaned surface was performed. After total graffiti removal, the cleaning action was interrupted in order to avoid to damage to the painted surface. If graffiti residuals visually remain on the surface, the removal was considered ineffective. 
To have an objective evaluation of removal action of the solvents, color and gloss changes were measured as indicated in the ASTM D6578 [18] standard. A KonicaMinolta $2500 \mathrm{cc}$ spectrophotometer (Tokyo, Japan) was used for color measurements, and an Erichsen NL3A digital glossmeter (Hemer, Germany) was used for gloss measurements. The gloss was measured as indicated in the ASTM D6578 standard, using a beam incident angle of $60^{\circ}$ following ISO 2813 [26] and ASTM D523 [27] standards, containing information about specular gloss measurement on nonmetallic specimens considering test geometry and apparatus characteristic. The color measurement was obtained with the spectrophotometer according to the CIE $L^{*} a^{*} b^{*}$ system using the SCE (specular component excluded) considering the Cartesian coordinates of the color space: $L^{*}, a^{*}$, and $b^{*}$. The color difference $\Delta E_{a b}^{*}$ is calculated using the following equation [28-30]:

$$
\Delta E_{a b}^{*}=\sqrt{\left(\Delta L^{*}\right)^{2}+\left(\Delta a^{*}\right)^{2}+\left(\Delta b^{*}\right)^{2}}
$$

Considering ASTM D6578 standard, the criteria of acceptability for the anti-graffiti properties is a maximum gloss variation of $10 \%$ and a maximum color variation $(\Delta E)$ of two points. However, the total number of cleaning cycles are not indicated to consider an acceptable result. As far as the operative procedure is concerned, the UNI 11246 standard [19] is very similar to the ASTM standard. In this standard, no removal agents are specified, and the acceptable threshold is $5 \%$ for gloss reduction measured at $60^{\circ}$ and one point in color variation $(\Delta E)$. Considering that the threshold related to the color variation is only slightly perceived by the human eye, UNI 11246 seems too restrictive. For this reason, the ASTM threshold will be considered throughout the paper. The color perception sensibility and the related acceptable thresholds are the objects of debate. Although a few research papers present in the literature propose different threshold values [31,32], to the best knowledge of the authors, no standard values are recognized. On the contrary, the UNI standard provides a threshold limit of ten maximum cleaning cycles, which was adopted as the limit value in this paper. The total standard deviation was calculated on 18 values obtained by measuring different spots from each cleaning area.

The ASTM D6578 standard indicates the possibility of evaluating the anti-graffiti behavior of materials subjected to outdoor or accelerated laboratory weathering. In fact, the aging of the organic coating due to UV irradiation would affect also its clean-ability and graffiti resistance. Considering the necessity to evaluate the properties in a reasonable time and to simultaneously produce a measurable damage, cyclic UV-B/humidity exposure was selected as the accelerated lab-scale test. The accelerated aging was performed with UV-B-313 lamps (where the number represents the characteristic nominal wavelength in nm of the peak of emission, Q-LAB, Westlake, OH, USA), according to ASTM G154 standard [33], which describes the basic principles for operating a fluorescent UV lamp and water apparatus. The cycle consisted of $8 \mathrm{~h}$ of UV exposure at $60{ }^{\circ} \mathrm{C}$ followed by $4 \mathrm{~h}$ of darkness and condensation at $50{ }^{\circ} \mathrm{C}$ for a total $1800 \mathrm{~h}$. After different exposure times, the color, the gloss, and the roughness were measured. The standard indicates to check the anti-graffiti properties at the end of the accelerated exposure time. However, to follow the influence of the produced damage on anti-graffiti behavior, more interesting results are expected by monitoring the evaluation of the surface cleanability after each cycle. As previously explained, it was carried out considering the color and gloss changes. In order to understand the cleaning mechanism on the aged surface, contact angle measurements were carried out following ASTM D7334 [34] standard, using a $20 \mu \mathrm{L}$ drop of distilled water. The contact angle was measured by digitally processing of the pictures, from optical stereomicroscope Stemi2000C (Carl Zeiss, Oberkochen, Germany).

The effect of the direct and prolonged exposure of the coatings to the solvent was investigated. The protective properties over solvent exposure time were evaluated by electrochemical impedance spectroscopy (EIS), which is a widely-used method to evaluate the corrosion behavior of painted metals [35,36]. The configuration of the test was inspired by ASTM D1308 standard [37], where the geometry test called "Spot Test, Open" is considered. At $23{ }^{\circ} \mathrm{C}$ and $50 \%$ relative humidity, a small portion of the reagent is placed on a horizontal surface (a specific standard procedure does not already 
exist for graffiti-resistant coating). A cylindrical PVC cell ensures the contact between solvent and coating surface for a fixed time. The amount of solvent was held constant for all the tests $(25 \mathrm{~mL})$. The same cell set-up was used for electrochemical impedance spectroscopy measurements, carried out in Harrison solution ( $3.5 \mathrm{wt} \%$ ammonium sulfate and $0.5 \mathrm{wt} \%$ sodium chloride), pouring the electrolyte after solvent removal. The tested area was $16.6 \mathrm{~cm}^{2}$. A three-electrode configuration was used: the sample as working electrode, a platinum wire counter electrode, and an $\mathrm{Ag} / \mathrm{AgCl}(+205 \mathrm{mV}$ vs. standard hydrogen electrode (SHE)) reference electrode. A Parstat 2273 potentiostat (Princeton Applied Research Ametek, Berwyn, PA, USA) was used for data acquisition. A frequency range between $10^{5}$ and $10^{-2} \mathrm{~Hz}$ with an amplitude of the signal of $30 \mathrm{mV}$ was employed. The impedance modulus in the low-frequency range was exploited to provide a rough estimation of the protection level of the organic coating [38,39].

\section{Results}

The principal aim of the method is to better understand the effect of the interaction between the coating and the removers, not only focusing on the coating. Table 1 reports the total removal cycles possible on both surfaces finishing with the two removers (following the procedures described in ASTM D6578 standard).

Table 1. Cycles of the total removal of graffiti following ASTM D6578 standard.

\begin{tabular}{ccc}
\hline Samples/Removers & MEK & Xylene \\
\hline Smooth S & 2 & 4 \\
Wrinkled W & 1 & 4 \\
\hline
\end{tabular}

The xylene shows a higher efficiency on both surface finishes. The MEK very effectively removed the graffiti, but at the same time interacts strongly with the paint, reducing the gloss values. Considering the color change, the wrinkled surface shows noticeable changes, probably due to the higher contact surface with the solvent, due to the higher roughness.

The color change with increasing cleaning cycles is shown in Figure 2. In this example, it is possible to see that the polar solvent (MEK) cannot remove the graffiti over the fourth cycle without producing a color change outside the ASTM threshold.
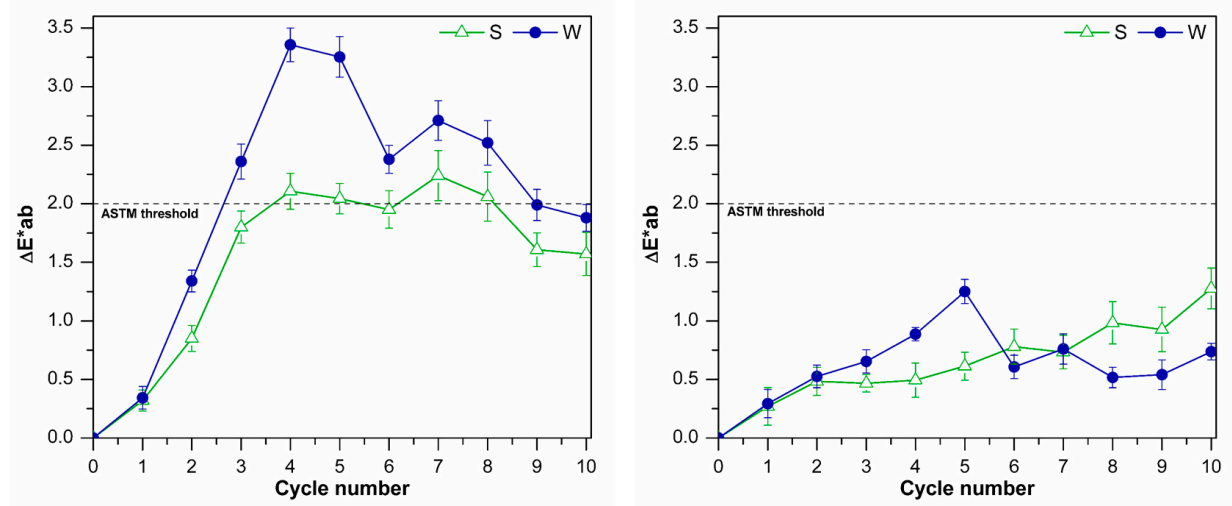

Figure 2. Color change as a function of the number of cleaning cycles using different removers: (a) Methyl ethyl ketone (MEK, polar); (b) Xylene (non-polar). Data extracted from [20].

The gloss variation was revealed to be more critical compared to the color variation (Figure 3). It is possible to observe that with the polar remover, the normalized gloss value exceeded the limit recommended by the standards after few cycles. In addition, the non-polar remover exceeded the limit value after only four removal actions. Considering the gloss changes with cycles, the sample with high roughness showed the worst behavior. 


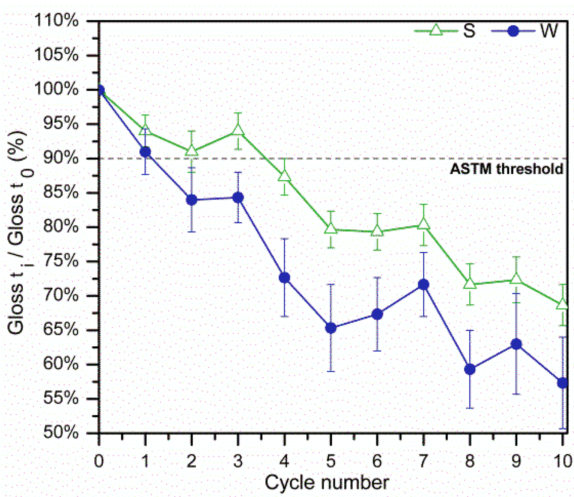

(a)

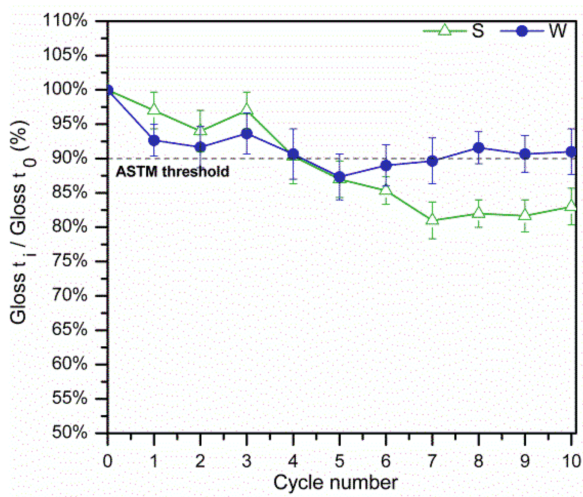

(b)

Figure 3. Cleaning gloss change as a function of the number of cleaning cycles using different removers: (a) MEK (polar); (b) Xylene (non-polar). Data extracted from [20].

The static contact angle was measured to verify the aging mechanism provided by the previous analysis. The measurements were repeated four times. During testing, the contact angle decreased for both samples (Figure 4), indicating an important modification of surface properties with an increase in hydrophilicity. To provide an easier comparison between the UV/humidity cycles and the contact angle measurements, "UV exposure time" and "total exposure time" are reported on the $x$-axis of Figure 4 . Considering that a cycle consists of $8 \mathrm{~h}$ of UV exposure followed by $4 \mathrm{~h}$ of humidity (as reported in Section 2), the "UV exposure time" results equal to $2 / 3$ of "total exposure time".

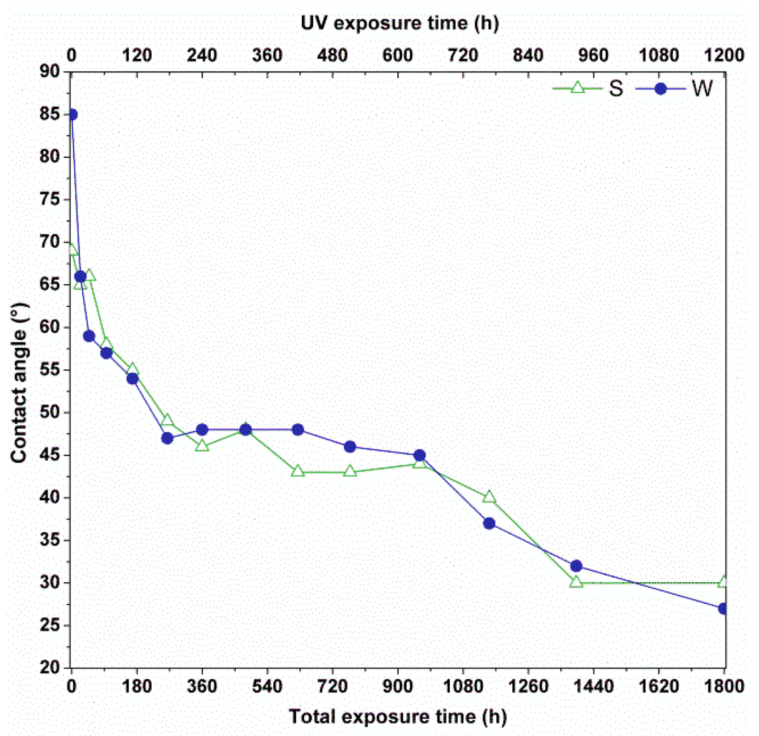

Figure 4. Contact angle as a function of the aging time.

The cleaning cycles analysis was carried out even on the aged surface to understand if the surface variation affects the graffiti cleanability. Table 2 shows the total UV-B cyclic exposure time, where the removal action is possible in accordance with the standard.

Table 2. Total UV-B exposure hours where the removal action results still effective.

\begin{tabular}{ccc}
\hline Samples/Removers & MEK & Xylene \\
\hline Smooth S & 264 & 264 \\
Wrinkled W & 96 & 168 \\
\hline
\end{tabular}


The chemical modification of the surface increased the graffiti adhesion. This caused a more difficult graffiti removal with both solvents. The polar one, having a stronger solubilization capability than the non-polar, better removed the graffiti, but at the same time produced higher gloss and color changes.

Electrochemical impedance spectroscopy was used to investigate the effect of the organic solvent exposure on the barrier properties of the organic coatings. During the solvent contact test, the organic solvent was not allowed to evaporate. After the solvent contact removal, the samples were conditioned at $20{ }^{\circ} \mathrm{C}$ to promote a partial evaporation from the soaked paint. Afterward, the samples were immersed in the electrolyte to carry out the EIS measurements. This procedure guarantees the partial inhibition of the polymer chains relocation after the organic solvent uptake. Therefore, it is believed to represent the coating behavior when an organic solvent is present (which is expected to lead to a barrier properties loss). The cycle aging test allows the solvent to partially evaporate before carrying out the electrochemical impedance spectroscopy measurements, and therefore the polymer chains have time to readapt, changing the original structure. This test is expected to highlight how much the coating can withstand contact-evaporation cycles before irreversible damages are formed.

To simplify the analysis, the impedance modulus in the low-frequency range was considered as an indication of the protection properties level of the organic coating. According to many reports [40-42], this property can be characterized by EIS measurements by examining the low-frequency limit of $|Z(\omega)|$ with an acceptable degree of approximation. In Figure 5, it is possible to observe how this value (total impedance $|Z|$ at $4 \times 10^{-2} \mathrm{~Hz}$ ) changes during contact time with MEK. Notice that the exposure promoted macroscopic phenomena due to the presence of water molecules and ions, such as swelling and then layer delamination. The test seems to be particularly tough for the samples with the wrinkled surface. After about 60 min of exposure, delamination of the paint from the substrate was observed, followed by the occurrence of cracks after about $200 \mathrm{~min}$. These results suggest that the contact time with the organic solvent can be dramatically detrimental for the corrosion protection properties. From a practical point of view, it seems that particular care has to be taken to reduce the organic solvent contact time during graffiti removal operations-in particular if MEK is used on polyurethane paint with wrinkled surfaces.

On the other hand, xylene showed no changes of the coatings' impedance modulus in the low-frequency range (stable around $10^{11} \Omega \mathrm{cm}^{2}$ ) for 360 min exposure time (not reported data). The noticeable differences observed compared to MEK are believed to rely on the apolar nature of xylene that probably does not affect the polyurethane intermolecular bonds.

It is important to highlight that the EIS measurements provide information on the reduction of corrosion protection properties of paints in a very short time (just a few hours).

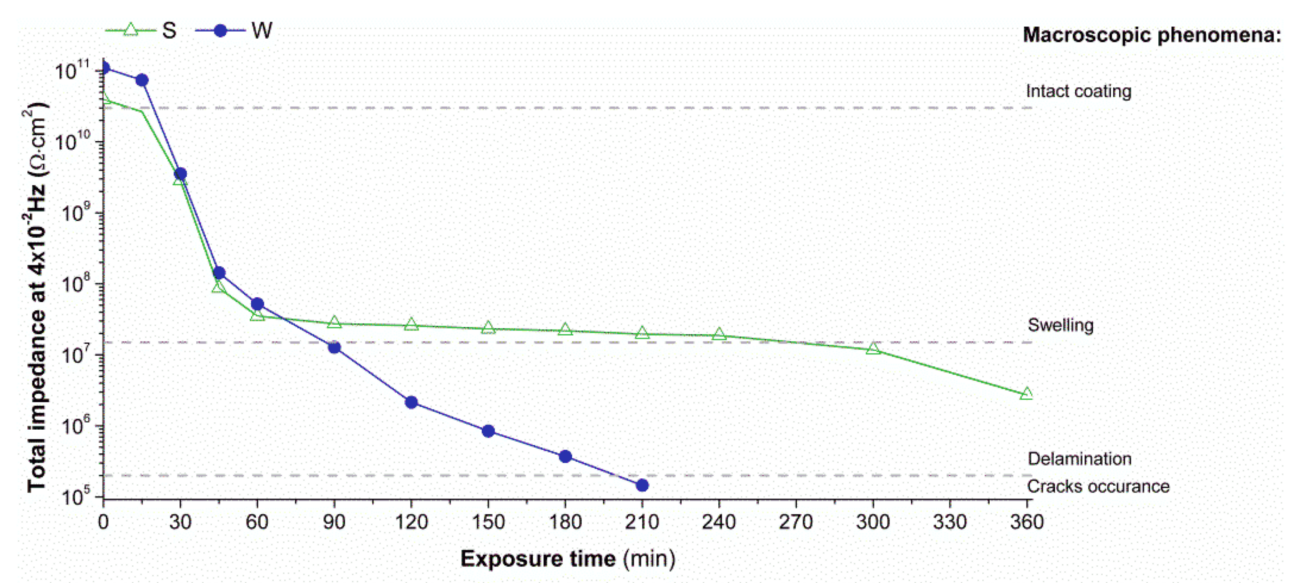

Figure 5. Impedance modulus at low frequency as a function of the aging time. 


\section{Conclusions}

The field of powder coatings for anti-graffiti applications is relatively new, and therefore the performance of the products currently on the market can be optimized. In addition, a test protocol could be individuated to evaluate the efficiency of removers, and at the same time, the resistance of organic coatings to chemical remover.

In this work, a critical analysis of the commonly employed standards for anti-graffiti evaluation has been carried out. First of all, it can be stated that when quantifying the characteristics of an anti-graffiti paint it is not sufficient to consider only the visual changes, but it is necessary to obtain a quantification by measuring the change of gloss and color. The acceptance criteria specified in ASTM 6578 standard have been revealed to be more suitable to evaluate the coatings. On the other hand, UNI 11246 standard suggests a maximum limit of graffiti and removals.

Considering the graffiti removers, the standards recommend to test several graffiti-removers. Among them, the experimental data suggest that the use of only of two types of organic solvents-one polar and one non-polar-provides a complete evaluation of the susceptibility of the coating to damage by the removal agent.

As far as the studied formulations are concerned, the following conclusions can be drawn:

- UV-B/condensation weathering exposure leads to a wettability variation, toward an increased hydrophilic behavior of the surface with a consequently more difficult graffiti removal with both removers.

- The criticism of the polar remover is probably due to the chemical interaction between the coating and the remover. The apolar remover presents less interaction with the coating.

- The coating properties are much more affected when the painted sheet is continuously immersed in the solvent with respect to the cyclic aging (wet/dry cycles).

- Considering the ease of graffiti removal, the surface finish shows a significant influence. An increase in the roughness of the paint makes the cleaning action less effective.

- Electrochemical impedance spectroscopy measurements are a very useful method to evaluate the damage produced on the coatings due to polishing action and contact with removers. In addition, the information of residual protection properties is quantitative, and a short time is necessary for its acquisition. This electrochemical approach is frequently used to check the protection properties of the organic coating; nevertheless, it is not just used to evaluate the interaction of graffiti removals and coatings.

- Finally, with a simple modification of an electrochemical cell, EIS measurements can also be carried out in-field, resulting in a suitable method to check the damage level of existing structures and components without the necessity of a laboratory.

Based on the obtained data, permanent coatings seem to be a possible solution for train cars exposed to vandalism. A design made in symbiosis with the remover, which studies in detail the interaction between coating, fouling spray, and solvent, could further accelerate the development of this sector.

Acknowledgments: The authors are grateful to Roberto Paganica (Akzo Nobel Italy, Como Italy) for powder coated samples supply.

Author Contributions: Stefano Rossi conceived and designed the research and experiments, analyzed the data and wrote the paper; Michele Fedel designed the experiments, analyzed and discussed the data; Simone Petrolli performed the experiments, analyzed the data and wrote the paper; Flavio Deflorian analyzed and discussed the data.

Conflicts of Interest: The authors declare no conflict of interest. 


\section{References}

1. Lettieri, M.; Masieri, M. Surface Characterization and Effectiveness Evaluation of Anti-Graffiti Coatings on Highly Porous Stone Materials. Appl. Surf. Sci. 2014, 288, 466-477. [CrossRef]

2. Watzlawik, M. The 'Art' of Identity Development-Graffiti Painters Moving Through Time and Space. Culture Psychol. 2014, 20, 404-415. [CrossRef]

3. Sanmartin, P.; Cappitelli, F.; Mitchell, R. Current Methods of Graffiti Removal: A Review. Constr. Build. Mater. 2014, 71, 363-374. [CrossRef]

4. Thompson, K.; Offler, N.; Hirsch, L.; Every, D.; Thomas, M. From broken windows to a renovated research agenda: A review of the literature on vandalism and graffiti in the rail industry. Transp. Res. A Policy Pract. 2012, 46, 1280-1290. [CrossRef]

5. Luongo, M. Quelli-che-dicono-no-ai-graffiti. Corriere della Sera Newspaper, 13 December 2014, p. 22.

6. Non Solo Graffiti Vandali Treni Costano Trenord Otto Milioni All'anno. Available online: http:// milano.corriere.it/milano/notizie/cronaca/14_gennaio_28/test-yoodeal.shtml?refresh_ce-cp (accessed on 18 March 2017).

7. Garcia, O.; Malaga, K. Definition of the Procedure to Determine the Suitability and Durability of an Anti-Graffiti Product for Application on Cultural Heritage Porous Materials. J. Cult. Herit. 2012, 13, 77-82. [CrossRef]

8. Bengtsson, T. Waterborne Wax-Based Sacrificial Graffiti Protective Coatings: Demands and Experience. In Proceedings of the European Coatings Conference Antigraffiti Coatings, Berlin, Germany, 2-3 December 1999; pp. 169-189.

9. Black, R.H. Anti-Graffiti Coating Material and Method of Using Same. U.S. Patent 5,387,434, 7 February 1995.

10. Neto, E.; Magina, S.; Camões, A.; Begonha, A.; Evtuguin, D.V.; Cachim, P. Characterization of concrete surface in relation to graffiti protection coatings. Constr. Build. Mater. 2016, 102, 435-444. [CrossRef]

11. Moura, A.; Flores-Colen, I.; de Brito, J. Study of the effect of three anti-graffiti products on the physical properties of different substrates. Constr. Build. Mater. 2016, 107, 157-164. [CrossRef]

12. Manvi, G.N.; Singh, A.R.; Jagtap, R.N.; Kothar, D.C. Isocyanurate Based Fluorinated Polyurethane Dispersion for Anti-Graffiti Coatings. Prog. Org. Coat. 2012, 75, 139-146. [CrossRef]

13. Rabea, A.M.; Mohseni, M.; Mirabedini, S.M.; Tabatabaei, M.H. Surface Analysis and Anti-Graffiti Behavior of a Weathered Polyurethane-Based Coating Embedded With Hydrophobic Nano Silica. Appl. Surf. Sci. 2012, 258, 4391-4396. [CrossRef]

14. Licchelli, M.; Marzolla, S.J.; Poggi, A.; Zanchi, C. Crosslinked Fluorinated Polyurethanes for the Protection of Stone Surfaces from Graffiti. J. Cult. Herit. 2011, 12, 34-43. [CrossRef]

15. Rossi, S.; Fedel, M.; Deflorian, F.; Feriotti, A. Anti-graffiti properties of polyurethane powder coatings. J. Test. Eval. 2017, in press. [CrossRef]

16. Chattopadhyay, D.K.; Raju, K.V.S.N. Structural Engineering of Polyurethane Coatings for High Performance Applications. Prog. Polym. Sci. 2007, 32, 352-418. [CrossRef]

17. Rossi, S.; Fedel, M.; Petrolli, S.; Deflorian, F. Accelerated weathering and chemical resistance of polyurethane powder coatings. J. Coat. Technol. 2016, 13, 427-437. [CrossRef]

18. ASTM D6578-13 Standard Practice for Determination of Graffiti Resistance; American Society for Testing and Materials: Philadelphia, PA, USA, 2013.

19. UNI 11246 Alluminio e Leghe di Alluminio-Modalità di Valutazione di Prodotto Permanente Anti-Graffiti; UNI, Enti Italiano di Normazione: Milano, Italy, 2007.

20. Papaj, E.A.; Mills, D.J.; Jamali, S.S. Complex shaped $\mathrm{ZnO}$ nano- and microstructure based polymer composites: mechanically stable and environmentally friendly coatings for potential antifouling applications. Prog. Org. Coat. 2014, 77, 2086-2090. [CrossRef]

21. Wicks, Z.W.; Jones, F.N.; Pappas, S.P. Organic Coatings, Science and Technology; John Wiley \& Sons: New York, NY, USA, 1992.

22. Rossi, S.; Fedel, M.; Petrolli, S.; Deflorian, F. Behaviour of different removers on permanent anti-graffiti organic coatings. J. Build. Eng. 2016, 5, 104-113. [CrossRef]

23. Powder Coating Technology Handbook; Engineers India Research Institute: Delhi, India, 2014.

24. Ulrich, D.L. User's Guide to Powder Coating, 3rd ed.; Society of Manufacturing Engineers: Dearborn, MI, USA, 1993. 
25. Acrilcolor. Available online: http:/ / arexons.it/ (accessed on 15 June 2016).

26. ISO 2813 Paints and varnishes-Determination of Gloss Value at 20 Degrees, 60 Degrees and 85 Degrees; International Organization for Standardization: Geneva, Switzerland, 2014.

27. ASTM D523-14 Standard Test Method for Specular Gloss; American Society for Testing and Materials: Philadelphia, PA, USA, 2014.

28. CIE 15 Technical Report: Colorimetry, 3rd ed.; International Commission on Illumination, Bureau Central de la CIE: Paris, France, 2004.

29. Precise Color Communication. Konica Minolta Sensing. Available online: http://www.konicaminolta.com/ instruments/about/network (accessed on 18 March 2017).

30. Gulrajani, M.L. Colour Measurement: Principles, Advances and Industrial Applications; Woodhead Publishing: Oxford, UK, 2016.

31. Sanmartín, P.; Silva, B.; Prieto, B. Effect of Surface Finish on Roughness, Color, and Gloss of Ornamental Granites. J. Mater. Civ. Eng. 2011, 23, 1239-1248. [CrossRef]

32. Prieto, B.; Sanmartín, P.; Pereira-Pardo, L.; Silva, B. Recovery of the traditional colours of painted woodwork in the Historical Centre of Lugo (NW Spain). J. Cult. Herit. 2011, 12, 279-286. [CrossRef]

33. ASTM G154-16 Standard Practice for Operating Fluorescent Ultraviolet (UV) Lamp Apparatus for Exposure of Nonmetallic Materials; American Society for Testing and Materials: Philadelphia, PA, USA, 2016.

34. ASTM D7334-13 Standard Practice for Surface Wettability of Coatings, Substrates and Pigments by Advancing Contact Angle Measurement; American Society for Testing and Materials: Philadelphia, PA, USA, 2013.

35. Macdonald, J.R. Impedance Spectroscopy: Emphasizing Solid Materials and Systems; Wiley: New York, NY, USA, 1987.

36. Scully, J.R.; Silverman, D.C.; Kendig, M.W. Electrochemical Impedance: Analysis and Interpretation; American Society for Testing and Materials: Philadelphia, PA, USA, 1993.

37. ASTM D1308-02 Standard Test Method for Effect of Household Chemicals on Clear and Pigmented Organic Finishes; American Society for Testing and Materials: Philadelphia, PA, USA, 2013.

38. Amirudin, A.; Thierry, D. Application of electrochemical impedance spectroscopy to the degradation of polymer-coated metals. Prog. Org. Coat. 1995, 26, 1-28. [CrossRef]

39. Rossi, S.; Deflorian, F.; Fontanari, L.; Cambruzzi, A.; Bonora, P.L. Electrochemical measurements to evaluate the damage due to abrasion on organic protective system. Prog. Org. Coat. 2005, 52, 288-297. [CrossRef]

40. Bierwagen, G.; Tallman, D.; Li, J.; He, L.; Jeffcoate, C. EIS studies of coated metals in accelerated exposure. Prog. Org. Coat. 2005, 46, 148-157. [CrossRef]

41. Hinderliter, B.R.; Croll, S.G.; Tallman, D.E.; Su, Q.; Bierwagen, G.P. Interpretation of EIS data from accelerated exposure of coated metals based on modeling of coating physical properties. Electrochim. Acta 2006, 51, 4505-4515. [CrossRef]

42. Olivier, M.G.; Romano, A.P.; Vandermiers, C.; Mathieu, X.; Poelman, M. Influence of the stress generated during an ageing cycle on the barrier properties of cataphoretic coatings. Prog. Org. Coat. 2008, 63, 323-329. [CrossRef]

(C) 2017 by the authors. Licensee MDPI, Basel, Switzerland. This article is an open access article distributed under the terms and conditions of the Creative Commons Attribution (CC BY) license (http:/ / creativecommons.org/licenses/by/4.0/). 